\title{
Synthesis of Nucleoside-based Phospholipid Amphiphiles ${ }^{\dagger}$
}

\author{
Hun Rok Jung, Tran Khac Vu, Seung Kyu Choi, Sun Min Park, and Byeang Hyean Kim*
}

\author{
Department of Chemistry, BK School of Molecular Science, Pohang University of Science and Technology, \\ Pohang 790-784, Korea.*E-mail: bhkim@postech.ac.kr \\ Received September 11, 2009, Accepted October 8, 2009
}

Key Words: Nucleoside, Phospholipids, Self-assembly

Phospholipids have been the subjects of considerable interest due to their importance in biological system. ${ }^{1}$ Conventional glycerol-based phospholipids such as phosphatidyl cholines self-assemble in water as spherical three dimensional closed structures known as liposomes. ${ }^{1 \mathrm{a}, 2}$ The potential applications of liposomes are numerous and include their uses as drug delivery materials, gene transfection agents and biological membrane model. ${ }^{3}$ Chemical modification at different parts of a phospholipid's structure can affect its activity in biological processes, especially in cell membrane. ${ }^{4}$ For the past several decades, a number of modifications of hydrophobic tail and hydrophilic head groups and structural variants of its glycerol units and carbohydrate-based phospholipids have been reported. ${ }^{5} \mathrm{Re}$ cently, the synthesis and physicochemical study of uridine-based phospholipids were reported. ${ }^{6}$ In this paper, we report the synthesis of cytidine-, guanosine-based phosphocholines having saturated acyl chain at 2'-, 3'- position of nucleosides as shown in Figure 1.

The synthetic scheme that we have used for the synthesis of nucleoside-based phospholipids is shown in Scheme 1 and 2. We used protecting groups such as tert-butyldimethylsilyl (TBDMS), tert-butoxycarbonyl (Boc), dimethylformamide dimethyl acetal and tetraisoproyl disiloxane for the protection of hydroxyl and amine groups of nucleosides. First, cytidine-based phospholipids were synthesized as in Scheme 1. The first step involved protection of the primary alcohol of 1 using TBDMS group.

Treatment of cytidine with TBDMS-Cl in the presence of
$N, N$-dimethylaminopyridine (DMAP) in pyridine gave selective 5'-OTBDMS-protected product 2 in $98 \%$ yield. Due to the high reactivity of nucleobase $\mathrm{NH}_{2}$, the TBDMS-protected cytidine was reacted with TMS-Cl in the presence of DMAP to protect 2',3'-hydroxyl group and then the amino group was protected by adding di-tert-butyl dicarbonate $\left((\mathrm{Boc})_{2} \mathrm{O}\right)$ to a solution of nucleoside in THF. Next, a 1-(3-dimethylaminopropyl)-3-ethylcarbo-diimide $\mathrm{HCl}$ (EDC) coupling of fatty acids in the presence of DMAP in $\mathrm{CH}_{2} \mathrm{Cl}_{2}$ gave corresponding esters in good yields. After completion of the reaction, the solvents were removed under vacuum and without further purification of the esters, a solution of $1 \mathrm{M}$ tetrabuthylammonium fluoride (TBAF) in THF was added to cleave TBDMS protecting group. We obtained compounds $4 a-4 e$ in up to $65 \%$ yield in this method.

The synthesis of compounds 5a-5e was achieved by first reacting 2-chloro-1,3,2-dioxaphospholane and $\mathrm{N}, \mathrm{N}$-diisopropylethylamine (DIPEA) in THF and subsequent oxidation of phosphorous (III) to phosphorous (V) by dropwise addition of $\mathrm{Br}_{2}$ at $0{ }^{\circ} \mathrm{C}$ over a period of $1 \mathrm{hr} .{ }^{7}$ Then the solvent was removed

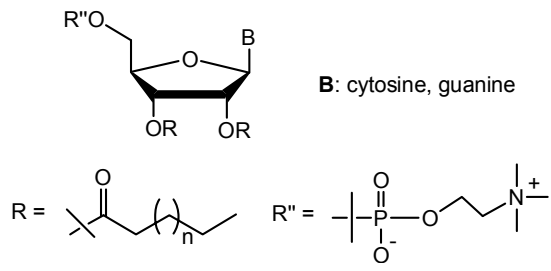

Figure 1. Nucleoside-based phospholipids and various acyl groups.

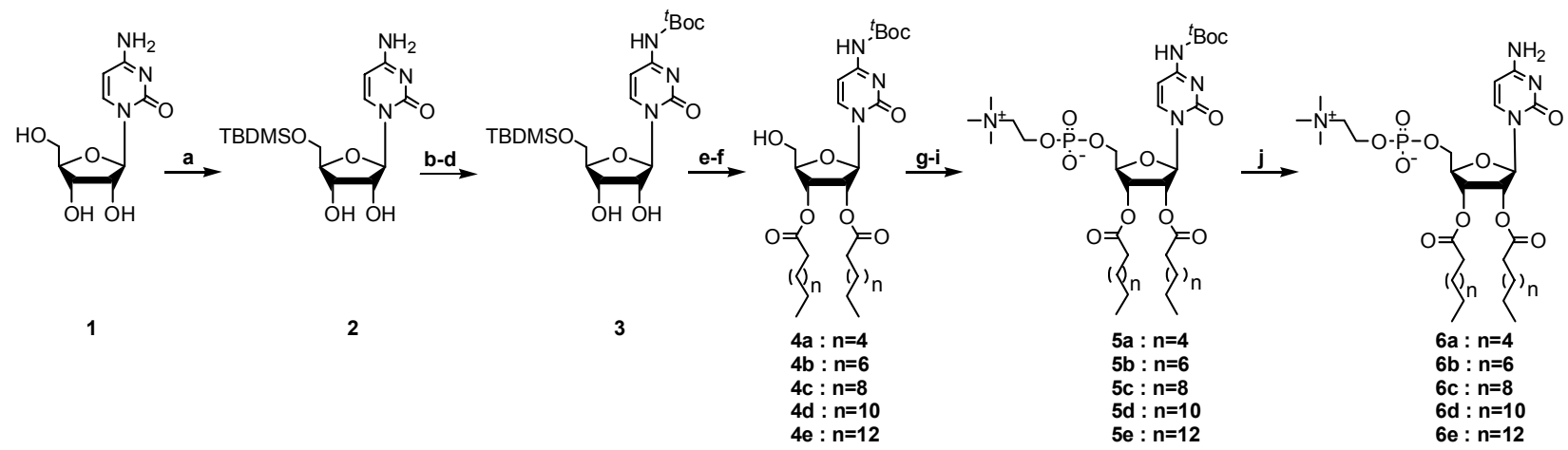

Scheme 1. Reagent and condition: a) TBDMS-Cl, DMAP, Py, 93\%; b) TMS-Cl, DMAP, THF; c) (Boc) ${ }_{2} \mathrm{O}$, THF; d) $\mathrm{H}_{2} \mathrm{O}$, THF (88\% three steps); e) fatty acid, EDC, DMAP, $\mathrm{CH}_{2} \mathrm{Cl}_{2}$; f) $1 \mathrm{M}$ TBAF in THF, THF (4a: $80 \%$; $\mathbf{4 b}: 78 \% ; \mathbf{4 c}: 69 \% ; \mathbf{4 d}: 72 \% ; \mathbf{4 e}: 65 \%$ two steps); g) 2-chloro-1,3,2-dioxaphospholane, DIPEA, THF; h) $\mathrm{Br}_{2}, \mathrm{THF}, 0{ }^{\circ} \mathrm{C}$; i) $40 \% \mathrm{Me}_{3} \mathrm{~N}, \mathrm{CHCl}_{3} / \mathrm{i}-\mathrm{PrOH} / \mathrm{CH}_{3} \mathrm{CN}=3 / 5 / 5,3 \mathrm{days}(\mathbf{5 a}: 67 \%, \mathbf{5 b}: 72 \%$, 5c : 60\%, 5d : 65\%, 5e : 61\% three steps); j) Phenol (3 M), TMS-Cl (1 M), $\mathrm{CH}_{2} \mathrm{Cl}_{2},(\mathbf{6 a}: 71 \%, \mathbf{6 b}: 65 \%, \mathbf{6 c}: 47 \%, \mathbf{6 d}: 65 \%, \mathbf{6 e}: 43 \%)$. 


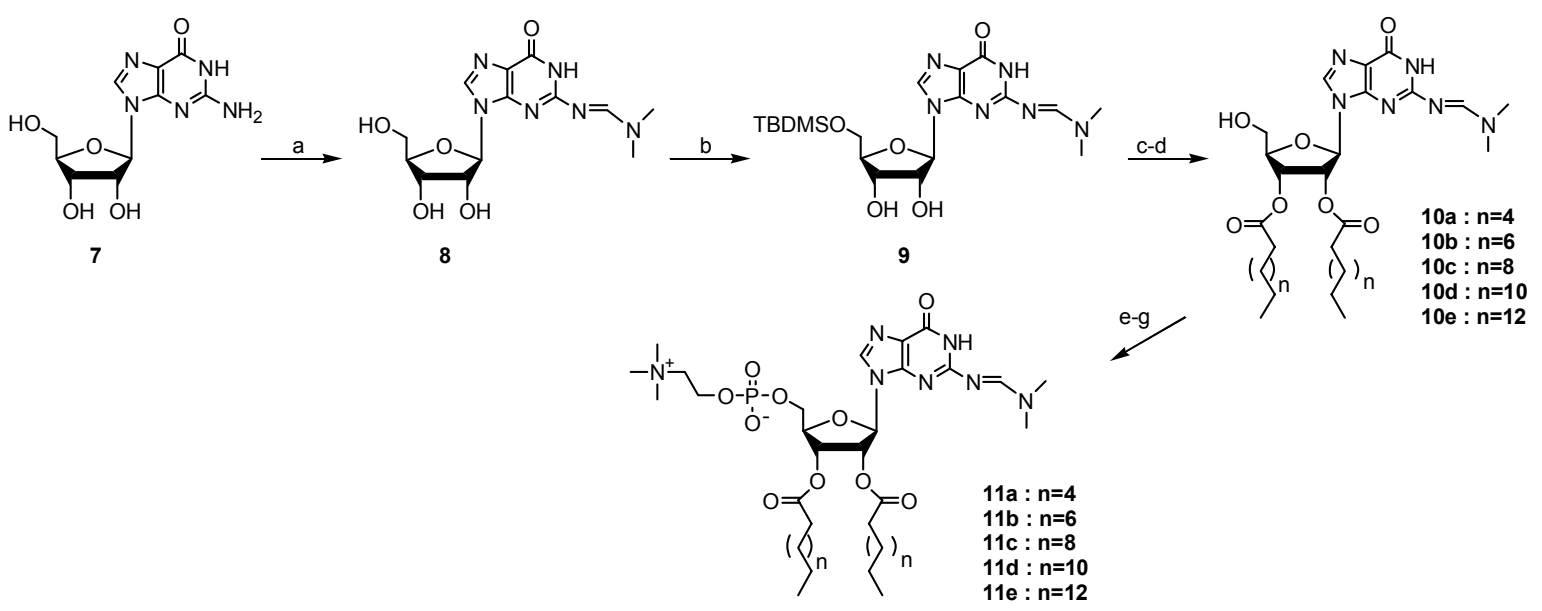

Scheme 2. Reagent and condition: a) $\mathrm{HC}(\mathrm{OMe})_{2} \mathrm{NMe}_{2}, \mathrm{MeOH}, 92 \%$; b) TBDMS-Cl, DMAP, Py/DMSO=2/1, 84\%; c) fatty acid, EDC, DMAP, $\mathrm{CH}_{2} \mathrm{Cl}_{2}$; d) $1 \mathrm{M}$ TBAF in THF, THF $(\mathbf{1 0 a}: 92 \%, \mathbf{1 0 b}: 96 \%, \mathbf{1 0 c}: 94 \%, \mathbf{1 0 d}: 91 \%$, 10e : 89\% two steps); e) 2-chloro-1,3,2-dioxaphospholane, DIPEA, THF; f) $\mathrm{Br}_{2}$, THF, $0{ }^{\circ} \mathrm{C}$; g) $40 \% \mathrm{Me}_{3} \mathrm{~N}, \mathrm{CHCl}_{3} / i-\mathrm{PrOH} / \mathrm{CH}_{3} \mathrm{CN}=3 / 5 / 5,3$ days $(\mathbf{1 1 a}: 25 \%, 11 \mathbf{b}: 24 \%, \mathbf{1 1 c}: 25 \%, \mathbf{1 1 d}: 23 \%, 11 \mathrm{e}: 24 \%$ three steps).

under reduced pressure. The residue was taken up in a mixture of $\mathrm{CH}_{3} \mathrm{CN} / \mathrm{i}-\mathrm{PrOH} / \mathrm{CHCl}_{3}$ (5:5:3) and $40 \%$ aqueous trimethylamine was added. After the mixture was stirring for 3 days, the solvent was removed; the residue was purified by flash chromatography (gradient elution by increasing the ratio of water from $\mathrm{CHCl}_{3} / \mathrm{MeOH} / \mathrm{H}_{2} \mathrm{O}=14: 5: 0.1$ to a final mixture of $\mathrm{CHCl}_{3} /$ $\left.\mathrm{MeOH} / \mathrm{H}_{2} \mathrm{O}=14: 5: 0.6\right)$. The overall yields for three steps were $60 \sim 72 \%$. By deprotecting the Boc group, we could obtain the final products $6 \mathbf{a}-6 \mathrm{e}$ in $43 \sim 71 \%$ yields. ${ }^{8}$ The final products were characterized by HR-FAB mass spectrometry as well as by ${ }^{1} \mathrm{H},{ }^{13} \mathrm{C},{ }^{31} \mathrm{P}$ NMR spectroscopy and other methods. ${ }^{9}$

Guanosine-based phospholipids were synthesized as shown in Scheme 2. First, we protected amine group with dimethylformamide dimethyl acetal. The reaction was carried out in $\mathrm{MeOH}$. After completion of the reaction, the residue was filtered. The remaining reactions were carried out with the same procedures as described for the synthesis of cytidine-based phopholipids. The overall yields for the final products 11a-11e were not so good in comparison to cytidine derivatives.

In summary, we have devised an efficient synthetic method for nucleoside-based phospholipids (cytidine and guanosine). These compounds may be used for various purposes such as drug delivery, gene transfection, and other biomedical applications.

Acknowledgments. We are grateful to NRF for financial support through the Gene Therapy R\&D and KNRRC program.

\section{References}

1. (a) Ross, M. Vesicles; Marcel Dekker Inc: New York, 1996. (b) Hanhan, D. J. A Guide to Phospholipid Chemistry; Oxford University Press: New York, 1997. (c) Cevc, G., Ed. Phospholipids Handbook; Marcel Dekker: New York, 1993.
2. Zare, R. N.; Modi, B. P.; Chiu, D. T.; Orwar, O.; Moscho, A. Proc. Natl. Acad. Sci. 1996, 93, 11443-11447.

3. (a) Guo, X.; Szoka, F. C. Acc. Chem. Res. 2003, 36, 335-341. (b) Woodle, M. C.; Lasic, D. D. Biochim. Biophys. Act. 1992, 1113, 171-199. (c) Shohda, K.; Toyota, T.; Yomo, T.; Sugawara, T. ChemBioChem 2003, 4, 778-781. (d) Venkatesan, N.; Kim, B. H. Chem. Rev. 2006, 106, 3712-3761. (e) Seo, Y. J.; Jeong, H. S.; Bang, E. K.; Hwang, G. T.; Jung, J. H.; Jang, S. K.; Kim, B. H. Bioconjugate Chem. 2006, 17, 1151-1155. (f) Venkatesan, N.; Seo, Y. J.; Bang, E. K.; Park, S. M.; Lee, Y. S.; Kim, B. H. Bull. Korean Chem. Soc. 2006, 27, 613-630.

4. (a) Bandoh, K.; Aoki, J.; Hosono, H.; Kobayashi, S; Kobayashi, T.; Murofushi, K. M.; Tsijumoto, M.; Arai, H.; Inoue, K. J. Biol. Chem. 1999, 247, 27776-27785. (b) Gueguen, G.; Gaige, B.; Grevy, J. M.; Rogalle, P.; Bellan, J.; Wilson, M.; Klaebe, A.; Pont, F.; Simon, M. F.; Chap, H. Biochemistry 1999, 38, 8440-8450. (c) Sugiura, T.; Nakane, S.; Kishimoto, S.; Waku, K.; Yoshioka, Y.; Tokumura, A.; Hanahan, D. J. Biochim. Biophys. Acta 1999, 1440, 194-204.

5. (a) Wissner, A.; Schaub, R. E.; Sum, P. E.; Kohler, C. A.; Goldstein, B. M. J. Med. Chem. 1985, 28, 1181-1187. (b) Eibl, H. Chem. Phys. Lipids 1980, 26, 405-429. (c) Ramirez, F.; Marecek, J. F. Synthesis 1985, 449-488. (d) Menger, F. M.; Wong, Y. L. J. Org. Chem. 1996, 61, 7382-7390. (e) Lindberg, J.; Ekeroth, J.; Konradsson, P. J. Org. Chem. 2002, 67, 194-199. (f) Menger, F. M.; Chen, X. Y. Tetrahedron Lett. 1996, 37, 323-326. (g) Sommerdijk, N. A. J. M.; Hoeks, T. H. L; Synak, M.; Feiters, M. C.; Nolte, R. J. M.; Zwanenburg, B. J. Am. Chem. Soc. 1997, 119, 4338-4344. (h) Hird, G. S.; McIntosh, T. G.; Grinstaff, M. W. J. Am. Chem. Soc. 2000, 122, 8097-8098.

6. (a) Moreau, L.; Barthelemy, P.; El Maataoui, M.; Grinstaff, M. W. J. Am. Chem. Soc. 2004, 126, 7533-7539. (b) Choi, S. K.; Vu, T. K.; Jung, J. M.; Kim, S. J.; Jung, H. R.; Chang, T.; Kim, B. H. ChemBioChem 2005, 6, 432-439.

7. Erukulla, R. K.; Byun, H.; Bittman, R. Tetrahedron Lett. 1994, 35, 5783-5784.

8. Kaiser, E.; Tam, J. P.; Kubiak, T. M.; Merrifield, R. M. Tetrahedron Lett. 1988, 29, 303-306.

9. Preliminary results of the cytidine derivatives were reported. Vu, T. K.; Kim, B. H. Advances in Natural Sciences 2005, 6, 59-67. 